\section{Bao, Dunn, Mhaisalkar, Schwaiger, and Shinde to chair 2019 MRS Spring Meeting}

www.mrs.org/spring2019

$\mathrm{T}^{\mathrm{n}}$

he Meeting chairs for the 2019 Ma-

terials Research Society (MRS)

Spring Meeting are Yuping Bao (The University of Alabama, USA), Bruce Dunn (University of California, Los Angeles, USA), Subodh Mhaisalkar (Nanyang Technological University, Singapore), Ruth Schwaiger (Karlsruhe Institute of Technology-Institute for Applied Materials, Germany), and Subhash L. Shinde (University of Notre Dame, USA). The Meeting will be held April 22-26, 2019, in Phoenix, Ariz.

Yuping Bao is an associate professor of chemical and biological engineering at The University of Alabama, USA. She

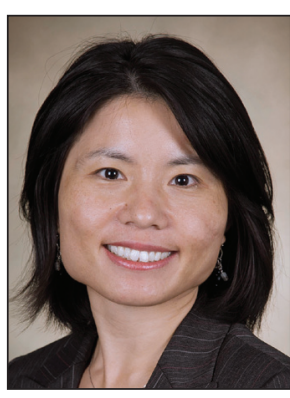

received her BS degree in chemistry from East China University of Science and Technology, China, and then earned her master's degree in nanomaterials research in the Physics Department of Tongji University, China. She received her $\mathrm{PhD}$ dual degree in materials science and engineering and in nanotechnology from the University of Washington, USA, in 2006.

After two and half years of postdoctoral research in the Center for Integrated Nanotechnology at Los Alamos National Laboratory, USA, Bao joined the Department of Chemical and Biological Engineering at The University of Alabama, Tuscaloosa, in 2008. In 2009, she was named a ReichholdShumaker Fellow and became an adjunct faculty member in biological science. Her current research interests are focused on rationally designed nanomaterials for biomedical applications, such as drug delivery and magnetic resonance imaging. She is a recipient of the 2010 Ralph Powe Junior Faculty Enhancement Award and a National Science
Foundation Career Award in 2012. She currently serves on the editorial board of the journal Biological Trace Element Research. She also serves on the MRS Government Affairs Committee.

Bruce Dunn is the Nippon Sheet Glass Professor of Materials Science and Engineering at the University of Califor-

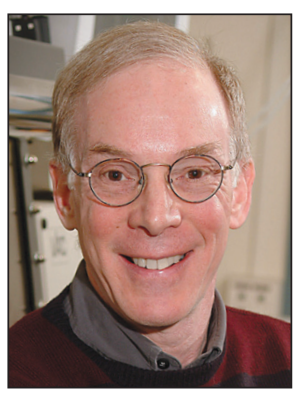
nia, Los Angeles (UCLA). He received his $\mathrm{PhD}$ degree in 1974

Previously, he was a staff scientist at the General Electric Research and Development Center, USA. His research interests concern the synthesis of inorganic and organic/inorganic materials, and characterization of their electrical, optical, biological, and electrochemical properties. A continuing theme in his research is the use of sol-gel methods to synthesize materials with designed microstructures and properties. His recent work on electrochemical energy storage includes three-dimensional batteries and pseudocapacitor materials.

Among the honors he has received are a Fulbright Research Fellowship, the Orton Lectureship from the American Ceramic Society, two awards from the US Department of Energy for outstanding research in materials science, and invited professorships in France, Japan, and Singapore. He is a Fellow of MRS and the American Ceramic Society, and a member of the World Academy of Ceramics. In addition to serving on the Board of Reviewing Editors at the journal Science, he is a member of the editorial boards of the journals Advanced Energy Materials, Solid State Ionics, Advanced Electronic Materials, and Journal of the American Ceramic Society. from UCLA.
Subodh Mhaisalkar is the Tan Chin Tuan Centennial Professor in the School of Materials Science and Engineering at Nanyang Technological University

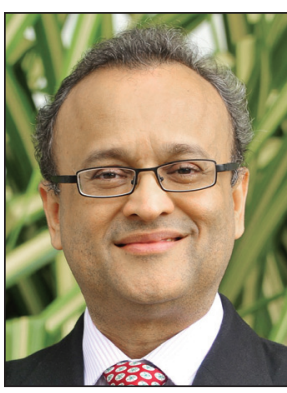

(NTU), Singapore. He is also the Executive Director of the Energy Research Institute at NTU (ERI@N), apanUniversity multidisciplinary research insti-

tute for innovative energy solutions. ERI@N has 225 full-time staff and 154 $\mathrm{PhD}$ scholarships, and has set up more than 60 industry partnership projects, including joint laboratories (on the NTU campus) with global industry leaders. He received his bachelor's degree from the Indian Institute of Technology Bombay, India, and his $\mathrm{MS}$ and $\mathrm{PhD}$ degrees from The Ohio State University, USA.

Prior to joining NTU in 2001, Mhaisalkar had more than 10 years of research and engineering experience in the microelectronics industry, where he held senior managerial positions at STATS Singapore, National Semiconductor, and the Singapore Institute of Manufacturing Technology. His areas of expertise and research interests include semiconductor technology, perovskite solar cells and light-emitting diodes, printed electronics, and energy storage.

Ruth Schwaiger is a senior scientist at the Karlsruhe Institute of TechnologyInstitute for Applied Materials (KIT) and head of the Nanomechanics Research

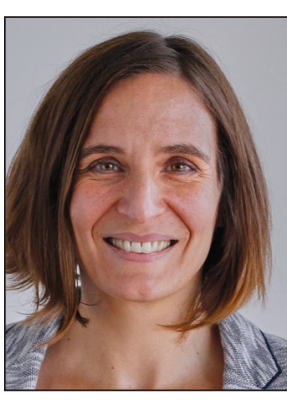
Group, Germany. She studied physics at TU Wien, Austria; conducted her doctoral research at the Max Planck Institute for Metals Research, Germany; and obtained her $\mathrm{PhD}$ degree in materials science in 2002 from the University of Stuttgart, Germany.

After postdoctoral research at the Massachusetts Institute of Technology 
(MIT), Schwaiger joined the Forschungszentrum Karlsruhe, Germany, in 2004 and then moved to a management consulting firm in 2007. She joined KIT in 2010. Her research interests range from deformation mechanisms in metals and the mechanics of small-scale materials and structures to biomechanics and mechanical metamaterials. Her research aims to develop a mechanism-based understanding of deformation and failure of materials, and to determine principles for the design toward improved strength and damage tolerance. Schwaiger has (co-)authored more than 50 publications, given more than 30 invited presentations at conferences, and co-organized 10 international symposia and workshops.
Subhash L. Shinde joined the Center for Sustainable Energy at the University of Notre Dame (ND Energy) in November 2016 as the associate director.

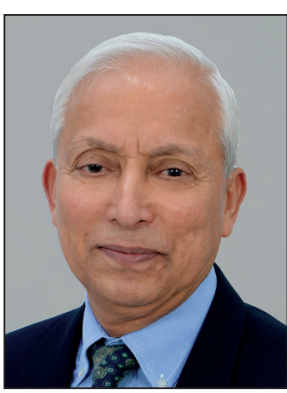

He leads ND Energy's research initiatives in research and global development and corporate programs. He received his BTech and MTech degrees in metallurgical engineering from the Indian Institute of Technology Bombay, India, and his $\mathrm{PhD}$ degree in materials science from Stanford University, USA.
Previously, he held various leadership positions in research for 18 years in the Microelectronics Division of the IBM T.J. Watson Research Center, USA. He was on the research staff and then a manager of the Concentrating Solar Technologies Group at Sandia National Laboratories, USA, from 2004 until 2012. Shinde has more than 40 publications, including three edited books and a book chapter. He holds more than 65 US patents and another 18 internationally. His research interests include advanced materials for efficient energy-conversion applications. He has given several invited presentations, and has been a symposium organizer for several MRS symposia.

\section{MRS invites nominations for awards program}

$\mathrm{T}$ he Materials Research Society (MRS) is seeking nominations for the Von Hippel Award, the David Turnbull Lectureship, the MRS Medal, the Materials Theory Award, the MRS Nelson "Buck" Robinson Science and Technology Award for Renewable Energy, and The Kavli Foundation Early Career Lectureship in Materials Science. The nomination site is open March 1-April 1, 2018. These awards will be presented at the 2018 MRS Fall Meeting, November 25-30, in Boston.

The MRS Awards Program recognizes outstanding contributors to the progress of materials research and acknowledges their exciting and profound accomplishments. Nomination forms and details about eligibility and nomination criteria are available from the Materials Research Society website at www.mrs.org/awards.

\section{Von Hippel Award acknowledges outstanding interdisciplinary work in materials research}

The Von Hippel Award, first presented to Arthur R. von Hippel, whose interdisciplinary and pioneering research typified the spirit of the award, is the
Society's highest honor. The recipient is recognized for brilliance and originality of intellect, combined with vision that transcends the boundaries of conventional scientific disciplines. The award includes a \$10,000 cash prize, honorary membership in MRS, and a unique trophy - a mounted ruby laser crystal, symbolizing the many faceted nature of materials research.

\section{Turnbull Lectureship honors career of an outstanding researcher and communicator}

The David Turnbull Lectureship recognizes the career of a scientist who has made outstanding contributions to understanding materials phenomena and properties through research, writing, and lecturing, as exemplified by the life work of David Turnbull. While honoring the accomplishments of the recipient, the David Turnbull Lectureship is intended to support and enrich the materials research community. The recipient will give a technical lecture of broad appeal at a designated session of the 2018 MRS Fall Meeting. The Turnbull Lecturer will receive a $\$ 5,000$ honorarium and a citation plaque.

\section{MRS Medal recognizes recent discovery or advancement in materials science}

The MRS Medal recognizes an exceptional achievement by an individual in materials research. The Medal is awarded for a specific outstanding recent discovery (approximately in last 10 years) or advancement that is expected to have a major impact on the progress of any materials-related field. The award consists of a $\$ 5,000$ cash prize, an engraved and mounted medal, and a citation certificate.

\section{Materials Theory Award honors advances made in materials structure and behavior}

The Materials Theory Award recognizes exceptional advances made by materials theory to the fundamental understanding of the structure and behavior of materials. This award is intended to honor both those who have pioneered the development of a new theoretical approach and those who have used existing approaches to provide significant new insight into materials behavior. The annual award consists of a $\$ 5,000$ cash prize, a presentation trophy, and a 